\title{
Tratamentos alternativos no controle da antracnose e sobre a qualidade de goiabas 'Pedro Sato'
}

\author{
Ivan Herman Fischer ${ }^{1}$, Maria Cecília de Arruda Palharini ${ }^{1}$ Mirian de Souza Fileti ${ }^{1}$, Antônio Fernandes Nogueira \\ Júnior $^{2}$, Marise Cagnin Martins Parisi ${ }^{3}$
}

${ }^{1}$ Polo Regional Centro Oeste / APTA. Avenida Rodrigues Alves, 40-40, 17030-000 Bauru-SP-Brasil; ${ }^{2}$ ESALQ/USP, Departamento de Fitopatologia e Nematologia; ${ }^{3}$ Polo Regional Centro Sul / APTA

Autor para correspondência: Ivan Herman Fischer(ihfische@apta.sp.gov.br)

Data de chegada: 16/03/2015. Aceito para publicação em: 15/03/2016.

$10.1590 / 0100-5405 / 2077$

\section{RESUMO}

Fischer, I.H.; Palharini, M.C.A.; Fileti, M.S.; Nogueira Júnior, A.F.; Parisi, M.C.M.Tratamentos alternativos no controle da antracnose e sobre a qualidade de goiabas 'Pedro Sato'. Summa Phytopathologica, v.42, n.4, p.333-339, 2016.

Um dos grandes problemas na comercialização de goiabas é a incidência de doenças pós-colheita que coincide com o amadurecimento dos frutos. Avaliou-se o efeito de produtos alternativos [fosfito de potássio, cloreto de cálcio, fécula de mandioca, 1-metilciclopropeno (1-MCP), etanol seguido de dicloro s. triazinatriona sódica dihidratada (etanol+cloro)] e de tratamento hidrotérmico, isoladamente e em associação, no controle da antracnose e nas características físico-químicas de goiabas 'Pedro Sato'. Os tratamentos foram realizados em goiabas naturalmente infectadas, em três estádios de maturação, armazenadas a 22 ou $25^{\circ} \mathrm{C}$ por oito dias. A incidência da antracnose foi avaliada pelos sintomas visuais e observação dos sinais do patógeno em microscópio óptico e os parâmetros físico-químicos avaliados foram cor da casca, firmeza da polpa, perda de massa fresca, sólidos solúveis, acidez titulável e ácido ascórbico. As associações de tratamentos etanol+cloro/fécula, hidrotérmico/ fécula e etanol+cloro/1-MCP reduziram a antracnose nos três estádios de maturação, em pelo menos algum período do armazenamento, promovendo um maior período de conservação dos frutos, com um atraso de dois a quatro dias no aparecimento da doença. A manutenção da qualidade das goiabas com as associações de tratamentos foram evidenciadas pelo atraso na mudança de coloração da casca e menor redução na firmeza da polpa, com destaque para etanol+cloro/1-MCP. Observou-se correlação positiva entre a incidência da antracnose e o estádio de maturação, expresso pela cor da casca do fruto. A maior eficiência das associações de tratamentos no controle da antracnose relacionou-se diretamente ao atraso no amadurecimento dos frutos, evidenciado pelos parâmetros cor da casca e firmeza da polpa.

Palavras-chave: podridão, Psidium guajava, Colletotrichum spp., manejo

\section{ABSTRACT}

Fischer, I.H.; Palharini, M.C.A.; Fileti, M.S.; Nogueira Júnior, A.F.; Parisi, M.C.M. Alternative treatments for anthracnose control and quality of 'Pedro Sato' guavas. Summa Phytopathologica, v.42, n.4, p.333-339, 2016.

One of the major problems in guava commercialization is the incidence of postharvest diseases, which coincides with fruit ripening. The effect of alternative products [potassium phosphite, calcium chloride, cassava starch, 1-methylcyclopropene (1-MCP), ethanol followed by sodium dichloro s. triazinetrione dehydrate (ethanol+chlorine)] and hydrothermal treatment, singly and in association, was evaluated on anthracnose control and on the physicochemical characteristics of 'Pedro Sato' guava. Treatments were applied to naturally infected guavas, in three maturity stages, which were stored at 22 or $25^{\circ} \mathrm{C}$ for eight days. The incidence of anthracnose was evaluated by visual observation of symptoms and signs of the pathogens under an optical microscope, and the evaluated physicochemical parameters were skin color, pulp firmness, fresh mass loss, soluble solids, titratable acidity and ascorbic acid. The association of treatments ethanol+chlorine/cassava starch, hydrothermal treatment/cassava starch and ethanol+chlorine/1-MCP reduced the incidence of anthracnose in all three maturity stages in at least one storage period, leading to longer shelf life of fruits and a delay of two to four days in the onset of the disease. The maintenance of guava quality by means of treatment association was evidenced by delayed change in the skin color and less reduction in pulp firmness, especially for ethanol+chlorine/1-MCP. There was a positive correlation between the incidence of anthracnose and the maturity stage, expressed by the fruit skin color. The higher efficiency of treatment association in controlling anthracnose was directly related to the delay in fruit ripening, evidenced by the parameters skin color and pulp firmness.

Keywords: rot, Psidium guajava, Colletotrichum spp., management

O estado de São Paulo destaca-se como o segundo maior produtor de goiaba (Psidium guajava L.) do Brasil, com aproximadamente 30\% da produção, destinada tanto ao consumo in natura, quanto à indústria (1). A cultivar Pedro Sato é a goiaba de polpa vermelha mais utilizada, apresentando frutos grandes, de casca rugosa, formato oblongo, polpa rosada, espessa e com poucas sementes (14).

A expansão da comercialização de frutos para o consumo in natura está intrinsecamente ligada à qualidade dos frutos e ao aumento da sua vida pós-colheita (18). Contudo, em função do seu alto metabolismo, a goiaba apresenta elevada perecebilidade. O estádio de maturação em que o fruto é colhido determina a qualidade a ser oferecida ao consumidor, devendo ser colhido após atingir a maturidade fisiológica, como forma de preservar suas qualidades organolépticas, preferencialmente no estádio 2 (cor da casca verde-clara) (6), quando apresentam boa resistência ao transporte e possuem boas características para o consumo. Frutos colhidos imaturos, além de baixa qualidade organoléptica são muito suscetíveis às desordens fisiológicas, enquanto frutos colhidos muito maduros entram rapidamente em senescência. $\mathrm{O}$ 
apodrecimento pela ação de patógenos aumenta a produção de etileno nos frutos e acelera o processo de amadurecimento, com consequente redução da vida útil dos frutos (18).

Algumas doenças pós-colheita da goiaba são quiescentes, ou seja, o patógeno infecta a fruta antes da colheita e permanece latente até o início do amadurecimento, como é o caso da antracnose, causada pelos complexos Colletotrichum gloeosporioides (Penz.) Sacc e $C$. acutatum Simmonds, e da pinta preta, causada por Guignardia psidii Ullasa \& Rawal. A incidência de doenças atinge valores superiores a 70\% em goiabas 'Pedro Sato' e 'Paluma' armazenadas por nove dias a $25^{\circ} \mathrm{C}$, causadas principalmente por Colletotrichum spp. $(35,5$ e $46,2 \%)$ e G. psidii (25,5 e 30,3\%) (12).

A falta de tecnologias de conservação limita o período de comercialização, com consequente redução do número de mercados consumidores. Para o controle de doenças pós-colheita existem técnicas químicas, físicas e biológicas, que podem atuar diretamente nos patógenos e/ou na fisiologia dos frutos, retardando seu amadurecimento e aumentando sua resistência. Devido à crescente restrição ao uso de fungicidas em pós-colheita, alternativas visando uma maior conservação estão sendo estudadas, algumas com certa eficiência em goiabas, como o tratamento hidrotérmico (11), o inibidor da ação do etileno (3), aplicações de cálcio, fosfitos (11), álcool (21) e uso de películas comestíveis, como a fécula de mandioca (7). A eficiência no controle da doença pode ser aumentada pela combinação de tratamentos, como observado para a antracnose em goiabas 'Pedro Sato', com os tratamentos hidrotérmico, 1-MCP e fosfito de potássio (11). Contudo, alguns estudos de conservação dos frutos acabam não caracterizando as doenças incidentes $(3,7)$ ou inoculam os patógenos em condições controladas de pós-colheita (21), carecendo de maiores estudos em condições naturais em que o patógeno infecta o fruto antes da colheita.

O tratamento de frutos com produtos alternativos e termoterapia têm a vantagem de não deixarem resíduos, além de não oferecer riscos à saúde humana e ao ambiente, podendo ser mais uma ferramenta a ser utilizada no controle integrado de doenças. Deste modo, o presente trabalho teve como objetivo avaliar o efeito de produtos alternativos e do tratamento hidrotérmico, isoladamente e em associação, no controle da antracnose da goiaba, decorrente de infecção natural no campo, e nas características físico-químicas de frutos colhidos em três estádios de maturação.

\section{MATERIAL E MÉTODOS}

As goiabas utilizadas nos experimentos foram da cultivar 'Pedro Sato', provenientes de pomar comercial com histórico de antracnose, localizado no município de Itajú/SP. Foram utilizados lotes uniformes, com frutos de tamanho médio, sem defeitos e com o estádio de maturação caracterizado com base na cor da casca, determinada com colorímetro Minolta, modelo CR 400, efetuando-se duas leituras na região equatorial do fruto e os resultados expressos em ângulo de cor $\left({ }^{\circ} \mathrm{h}\right)$, sendo estádio 1: cor da casca verde-escura, ângulo de cor $\left({ }^{\circ} \mathrm{h}\right)$ entre 120 e 117; estádio 2: cor da casca verde-clara, ${ }^{\circ} \mathrm{h}$ entre 116 e 113 e estádio 3: cor da casca verde-amarela, ${ }^{\circ} \mathrm{h}$ entre 112 e 108 (2).

Os experimentos foram divididos em três etapas. Na primeira, goiabas no estádio 2 de maturação foram submetidas a sete tratamentos (período de imersão): 1) água destilada (10 min tratamento testemunha); 2) $20 \mathrm{~g} \mathrm{~L}^{-1}$ de cloreto de cálcio (20 min); 3) fosfito de potássio $\left(40 \% \mathrm{P}_{2} \mathrm{O}_{5}+20 \% \mathrm{~K}_{2} \mathrm{O}\right.$ - 'Fitofós K plus' $\left.1,5 \mathrm{~mL} \mathrm{~L}^{-1}\right)$ (20 min) (11); 4) hidrotérmico em banho maria a $50^{\circ} \mathrm{C}(10 \mathrm{~min})(21)$;
5) $900 \mathrm{~nL} \mathrm{~L}^{-1}$ de 1-metilciclopropeno (1-MCP) durante três horas de exposição ao gás (3); 6) $30 \mathrm{~g} \mathrm{~L}^{-1}$ de fécula de mandioca (10 segundos) (7) e 7) etanol 50\% (5 min), seguido de dicloro s. triazinatriona sódica dihidratada a $0,2 \mathrm{~g} \mathrm{~L}^{-1}$ de cloro ativo ( $5 \mathrm{~min}$ ). Após secagem, os frutos foram individualizados em bandejas plásticas e submetidos por oito dias a $22^{\circ} \mathrm{C}$ e $80-85 \%$ de UR, em câmara frigorífica. A incidência da antracnose, decorrente de infecção natural no campo, foi avaliada visualmente a cada dois dias, identificando a doença com base na sintomatologia e na observação das estruturas (sinais) do agente causal sob microscópio óptico.

Os quatro tratamentos que proporcionaram maior redução na incidência da antracnose foram selecionados e avaliados em associação, aplicados de forma sequencial, novamente em frutos no estádio 2 de maturação (segunda etapa). $\mathrm{O}$ armazenamento dos frutos e a avaliação da antracnose foram realizados conforme descritos na primeira etapa, exceto pela temperatura de armazenamento. Optou-se por elevar a temperatura de 22 para $25^{\circ} \mathrm{C}$, de modo que a eficiência dos tratamentos fosse avaliada na condição ideal de desenvolvimento da antracnose (25).

$\mathrm{Na}$ terceira etapa, três combinações de tratamentos que proporcionaram redução na incidência de antracnose foram selecionadas e avaliadas novamente em frutos colhidos em três estádios de maturação $(1,2$ e 3$)$ e armazenados por oito dias a $22^{\circ} \mathrm{C}$, temperatura ambiente padrão de comercialização, e $80-85 \%$ de UR, em câmara frigorífica.

O delineamento experimental utilizado foi o inteiramente casualizado, em fatorial na terceira etapa do experimento (quatro tratamentos x três estádios de maturação), adotando-se três repetições de 5-10 frutos (repetições) para cada tratamento. Os experimentos foram repetidos duas vezes. A incidência da antracnose foi comparada entre os tratamentos e os estádios de maturação, durante o armazenamento, por meio de análise de variância e as médias comparadas pelo teste não paramétrico de comparação de múltiplas proporções $(\mathrm{p}<0,05)(26)$.

Em adição às avaliações de antracnose, na terceira etapa dos experimentos foi feita a caracterização físico-química dos frutos após a colheita e aos oito dias de armazenamento. As características físicoquímicas avaliadas foram: a) cor da casca, determinada usando-se colorímetro Minolta, modelo CR-400, efetuando-se duas leituras na região equatorial do fruto e os resultados expressos em ângulo de cor $\left({ }^{\circ} \mathrm{h}\right)$; b) firmeza da polpa, determinada com penetrômetro digital TR Turoni, modelo 53205 , ponteira $8 \mathrm{~mm}$, tomando-se leituras na região equatorial do fruto e os resultados expresso em Newton (N); c) perda de massa fresca $(\mathrm{g})$, determinada em balança de precisão com duas casas decimais e calculada pela diferença entre a massa inicial e a massa ao final de cada período de armazenamento e os resultados expressos em porcentagem (\%); d) teor de sólidos solúveis, determinado em refratômetro digital Atago, modelo PAL-1, e os resultados expressos em ${ }^{\circ}$ Brix; e) teor de acidez titulável, determinado por titulação com $\mathrm{NaOH} 0,1 \mathrm{~N}$ e os resultados expressos em \% de ácido cítrico; f) teor de ácido ascórbico, determinado por titulação com DCFI (2.6 diclorofenolindofenol de sódio) e os resultados expressos em mg $100 \mathrm{~g}^{-1}$ de polpa (5). O delineamento experimental foi o inteiramente casualizado em esquema fatorial (quatro tratamentos $\mathrm{x}$ três estádios de maturação), com três repetições de quatro frutos para cada tratamento. Cada parâmetro físico-químico avaliado foi comparado entre os tratamentos e estádios de maturação, por meio de análise de variância e as médias comparadas pelo teste de Tukey $(p<0,05)$. Os parâmetros físico-químicos foram correlacionados com a incidência de antracnose e, posteriormente, analisados pelo teste $\mathrm{F}(\mathrm{p}<0,05)$. 


\section{RESULTADOS}

Controle alternativo da antracnose da goiaba

$\mathrm{Na}$ primeira etapa do trabalho em que foram avaliados sete tratamentos, constatou-se redução significativa da antracnose com os tratamentos 1-MCP e hidrotérmico a partir do quarto dia de armazenamento (Tabela 1), seguido pelos tratamentos etanol+cloro e fécula de mandioca, a partir do sexto dia de armazenamento. Os tratamentos com fosfito de potássio e cloreto de cálcio foram ineficientes no controle da antracnose.

Os quatro tratamentos selecionados (fécula de mandioca, 1-MCP, hidrotérmico e etanol+cloro) e avaliados em associação de dois, aplicados de forma sequencial, reduziram os sintomas de antracnose na segunda etapa dos experimentos, com um atraso em relação ao tratamento testemunha de pelo menos quatro dias no aparecimento dos sintomas da doença (Tabela 2). Etanol+cloro/hidrotérmico e etanol+cloro/1-MCP inibiram totalmente a ocorrência de antracnose no segundo dia. Hidrotérmico/fécula e hidrotérmico/1-MCP destacaram-se até o quarto dia de armazenamento e a associação hidrotérmico/1-MCP destacou-se em relação aos demais tratamentos a partir do sexto dia de armazenamento.

A ocorrência da antracnose foi superior na segunda etapa do trabalho (Tabela 2) em relação à primeira etapa (Tabela 1). Analisandose a eficiência dos tratamentos isoladamente e em associação em relação ao respectivo tratamento testemunha, constata-se uma maior eficiência na média das associações dos tratamentos, com 78,3\% de redução de frutos com antracnose no quarto dia de armazenamento da etapa 2 , em relação ao sexto dia da etapa 1 , com $68,9 \%$ de redução na incidência, na média dos quatro tratamentos selecionados. Contudo, a partir do sexto dia de armazenamento $100 \%$ dos frutos apresentaram antracnose no tratamento testemunha e a eficiência relativa das associações de tratamentos foi reduzindo gradualmente até o oitavo dia. Optou-se por desconsiderar a seleção dos tratamentos etanol+cloro/hidrotérmico e hidrotérmico/1-MCP para a terceira etapa, pois constatou-se alta contaminação com pinta preta nestes tratamentos (dados não apresentados), o que atrapalha a avaliação da antracnose.

As três associações de tratamentos selecionadas para a terceira etapa (etanol+cloro/fécula, hidrotérmico/fécula e etanol+cloro/1MCP) controlaram a antracnose em mais de 50\% nos estádios 1 e 2 de maturação, com destaque para etanol+cloro/1-MCP ao final do armazenamento, com controle superior a 80\% (Tabela 3). Já no estádio 3 de maturação, o tratamento hidrotérmico/fécula destacou-se em relação aos demais, atrasando em pelo menos quatro dias os sintomas em relação ao tratamento testemunha e sendo o único tratamento a não ter um incremento da doença em função do estádio de maturação. A menor eficiência de controle da antracnose foi observada nos tratamentos etanol+cloro/fécula e etanol+cloro/1-MCP em frutos no estádio 3 de maturação. A eficácia de controle da antracnose observada com as três associações pode ser considerada equiparável aos resultados obtidos com os respectivos tratamentos na segunda etapa do trabalho.

Tabela 1. Efeito de tratamentos alternativos pós-colheita no controle da antracnose da goiaba 'Pedro Sato', durante oito dias de armazenamento a $22^{\circ} \mathrm{Ce} 80-85 \%$ de UR.

\begin{tabular}{|c|c|c|c|c|}
\hline \multirow{3}{*}{ Tratamentos } & \multicolumn{4}{|c|}{ Incidência (\%) da antracnose $e^{y}$} \\
\hline & \multicolumn{4}{|c|}{ - dias de armazenamento - } \\
\hline & 2 & 4 & 6 & 8 \\
\hline Testemunha (água) & $0 \mathrm{a}^{\mathrm{z}}$ & $19,0 \mathrm{~b}$ & $69,0 \mathrm{~d}$ & $92,9 \mathrm{c}$ \\
\hline Cloreto de Cálcio & $0 \mathrm{a}$ & $11,9 \mathrm{ab}$ & $66,7 \mathrm{~cd}$ & $100,0 \mathrm{c}$ \\
\hline Fosfito de potássio & $0 \mathrm{a}$ & $9,5 \mathrm{ab}$ & $61,9 \mathrm{~cd}$ & $95,2 \mathrm{c}$ \\
\hline Fécula de mandioca & $0 \mathrm{a}$ & $4,8 \mathrm{ab}$ & $35,7 \mathrm{bc}$ & $66,7 \mathrm{~b}$ \\
\hline Etanol+cloro & $0 \mathrm{a}$ & $2,4 \mathrm{ab}$ & $26,2 \mathrm{ab}$ & $54,8 \mathrm{~b}$ \\
\hline Hidrotérmico & $0 \mathrm{a}$ & $0,0 \mathrm{a}$ & $19,0 \mathrm{ab}$ & $45,2 \mathrm{ab}$ \\
\hline 1-MCP & $0 \mathrm{a}$ & $0,0 \mathrm{a}$ & $4,8 \mathrm{a}$ & $16,7 \mathrm{a}$ \\
\hline
\end{tabular}

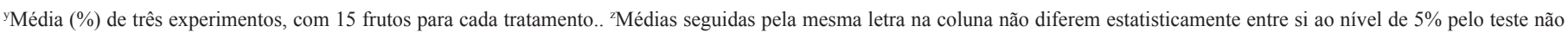
paramétrico de comparação de múltiplas proporções (Zar, 1999).

Tabela 2. Efeito de tratamentos alternativos pós-colheita no controle da antracnose da goiaba 'Pedro Sato', durante oito dias de armazenamento a $25^{\circ} \mathrm{C}$ e $80-85 \%$ de UR.

\begin{tabular}{|c|c|c|c|c|}
\hline \multirow{3}{*}{ Tratamentos } & \multicolumn{4}{|c|}{ Incidência (\%) da antracnose ${ }^{y}$} \\
\hline & \multicolumn{4}{|c|}{-dias de armazenamento- } \\
\hline & 2 & 4 & 6 & 8 \\
\hline Testemunha (água) & $18,9 b^{z}$ & $87,8 \mathrm{~d}$ & $100,0 \mathrm{~d}$ & $100,0 \mathrm{c}$ \\
\hline Etanol+cloro/hidrotérmico & $0,0 \mathrm{a}$ & $11,1 \mathrm{ab}$ & $71,1 \mathrm{c}$ & $82,2 \mathrm{~b}$ \\
\hline Etanol+cloro/fécula de mandioca & $4,4 \mathrm{ab}$ & $31,1 \mathrm{c}$ & $62,2 \mathrm{c}$ & $82,2 \mathrm{~b}$ \\
\hline Etanol+cloro/1-MCP & $0,0 \mathrm{a}$ & $26,7 \mathrm{bc}$ & $37,8 \mathrm{ab}$ & $72,2 \mathrm{ab}$ \\
\hline Hidrotérmico/fécula de mandioca & $1,1 \mathrm{a}$ & $4,4 \mathrm{a}$ & $37,8 \mathrm{ab}$ & $72,2 \mathrm{ab}$ \\
\hline Hidrotérmico/1-MCP & $1,1 \mathrm{a}$ & $5,6 \mathrm{a}$ & $22,5 \mathrm{a}$ & 59,6 a \\
\hline 1-MCP/fécula de mandioca & $8,9 \mathrm{ab}$ & $35,6 \mathrm{c}$ & $50,0 \mathrm{bc}$ & $64,4 \mathrm{ab}$ \\
\hline
\end{tabular}

${ }^{\mathrm{y}}$ Média (\%) de três experimentos, com 30 frutos para cada tratamento. ${ }^{2}$ Médias seguidas pela mesma letra na coluna não diferem estatisticamente entre si ao nível de $5 \%$ pelo teste não paramétrico de comparação de múltiplas proporções (Zar, 1999). 
Tabela 3. Efeito de tratamentos alternativos pós-colheita aplicados em goiabas 'Pedro Sato' com diferentes estádios de maturação na incidência (\%) de antracnose, durante oito dias de armazenamento a $22^{\circ} \mathrm{C}$ e $80-85 \%$ de UR.

\begin{tabular}{|c|c|c|c|}
\hline \multirow[t]{2}{*}{ Tratamentos } & \multicolumn{3}{|c|}{ Estádio de maturação ${ }^{y}$} \\
\hline & 1 & 2 & 3 \\
\hline & \multicolumn{3}{|c|}{-2 dias de armazenamento- } \\
\hline Etanol+cloro/fécula de mandioca & $0,0 \mathrm{aA}$ & $0,0 \mathrm{aA}$ & $4,4 \mathrm{aA}$ \\
\hline Etanol+cloro /1-MCP & $0,0 \mathrm{aA}$ & $0,0 \mathrm{aA}$ & $6,7 \mathrm{abA}$ \\
\hline Testemunha (água) & $2,2 \mathrm{aA}$ & $37,8 \mathrm{bB}$ & $64,4 \mathrm{bC}$ \\
\hline Etanol+cloro/fécula de mandioca & $0,0 \mathrm{aA}$ & $4,4 \mathrm{aA}$ & $42,2 \mathrm{bB}$ \\
\hline Etanol+cloro /1-MCP & $2,2 \mathrm{aA}$ & $8,9 \mathrm{aA}$ & $44,4 \mathrm{bB}$ \\
\hline Hidrotérmico/fécula de mandioca & $0,0 \mathrm{aA}$ & $2,2 \mathrm{aA}$ & $0,0 \mathrm{aA}$ \\
\hline Etanol+cloro /1-MCP & $4,4 \mathrm{aA}$ & $13,3 \mathrm{aA}$ & $66,7 \mathrm{bB}$ \\
\hline \multirow[t]{2}{*}{ Hidrotérmico/fécula de mandioca } & $2,2 \mathrm{aA}$ & $6,7 \mathrm{aA}$ & $6,7 \mathrm{aA}$ \\
\hline & \multicolumn{3}{|c|}{-8 dias de armazenamento- } \\
\hline Testemunha (água) & $93,3 \mathrm{cA}$ & $100,0 \mathrm{cA}$ & $100,0 \mathrm{cA}$ \\
\hline Etanol+cloro/fécula de mandioca & $17,8 \mathrm{abA}$ & $46,7 \mathrm{bB}$ & $88,9 \mathrm{bcC}$ \\
\hline Etanol+cloro /1-MCP & $4,4 \mathrm{aA}$ & $15,6 \mathrm{aA}$ & $71,1 \mathrm{bB}$ \\
\hline Hidrotérmico/fécula de mandioca & $26,7 \mathrm{bA}$ & $31,1 \mathrm{abA}$ & $37,8 \mathrm{aA}$ \\
\hline
\end{tabular}

${ }^{y}$ Média (\%) de três experimentos, com 15 frutos para cada tratamento. ${ }^{2}$ Médias seguidas pela mesma letra, minúscula na coluna e maiúscula na linha, não diferem estatisticamente entre si em nível de 5\% pelo teste não paramétrico de comparação de múltiplas proporções (Zar, 1999).

Caracterização físico-química dos frutos submetidos aos tratamentos alternativos

A perda de massa dos frutos foi semelhante entre os tratamentos $(\mathrm{p}<0,05)$ ao final do armazenamento, ou seja, os tratamentos não foram efetivos em retardar a perda de massa. Contudo, uma maior perda de massa foi observada conforme o avanço do estádio de maturação na colheita do fruto (Tabela 4). Em relação à cor da casca as três associações de tratamentos diferiram $(p<0,05)$ da testemunha. Diferenças na cor entre os estádios de maturação foram observadas, com redução no ângulo de cor conforme avanço da maturação. Houve retenção da firmeza em todos os tratamentos. O tratamento etanol+cloro/1-MCP apresentou melhor retenção de firmeza, sem diferir do tratamento etanol+cloro/fécula. Frutos em estádio de maturação mais avançado apresentaram menor firmeza durante o armazenamento (Tabela 4).

As associações de tratamentos não influenciaram significativamente o teor de sólidos solúveis dos frutos. Os frutos dos estádio 2 e 3 apresentaram menor teor de sólidos solúveis em relação aos frutos do estádio 1 (Tabela 5). Os frutos tratados com etanol+cloro/1-MCP apresentaram maior acidez, diferindo dos demais tratamentos $(p<0,05)$. Observa-se que os frutos apresentaram menor acidez nos estádios mais avançados de maturação. Em relação ao teor de ácido ascórbico, os tratamentos aplicados não influenciaram seu conteúdo. Diferenças entre os estádios de maturação foram observadas, com menor teor de ácido ascórbico no estádio 3 (Tabela 5).
Análise de correlação entre antracnose e parâmetros físicoquímicos

Observou-se correlação negativa $(\mathrm{r}=-0,79)$ para os parâmetros incidência de antracnose em relação ao parâmetro cor da casca, em goiabas amostradas em três estádios de maturação, e armazenadas por oito dias a $22^{\circ} \mathrm{C}$, ou seja, frutos com maior maturação (coloração amarela mais acentuada) apresentaram maior incidência da doença. Em relação aos demais parâmetros físico-químicos avaliados não foi observada correlação significativa em relação a incidência de antracnose, em frutos amostrados em três estádios de maturação.

Com relação à correlação entre a incidência da antracnose e os parâmetros físico-químicos em goiabas amostradas em três estádios de maturação e submetidas a diferentes tratamentos, armazenadas por oito dias a $22^{\circ} \mathrm{C}$, observou-se correlação negativa para antracnose e o parâmetro cor da casca em frutos submetidos as associações de tratamentos em pelo menos dois estádios de maturação (Tabelas 6). Correlação negativa também foi observada para antracnose em relação à firmeza da polpa nas associações mais eficientes no controle da doença ao final do armazenamento, etanol+cloro/1-MCP nos estádios de maturação 1 e 2 e hidrotérmico/fécula no estádio 3.

\section{DISCUSSÃO}

Os tratamentos 1-MCP, hidrotérmico, fécula de mandioca e etanol+cloro reduziram a incidência de antracnose em goiabas 'Pedro 
Tabela 4. Efeito de tratamentos alternativos pós-colheita aplicados em goiabas 'Pedro Sato' com diferentes estádios de maturação nas características físicas, durante oito dias de armazenamento a $22^{\circ} \mathrm{C}$ e $80-85 \%$ de $\mathrm{UR}^{\mathrm{y}}$.

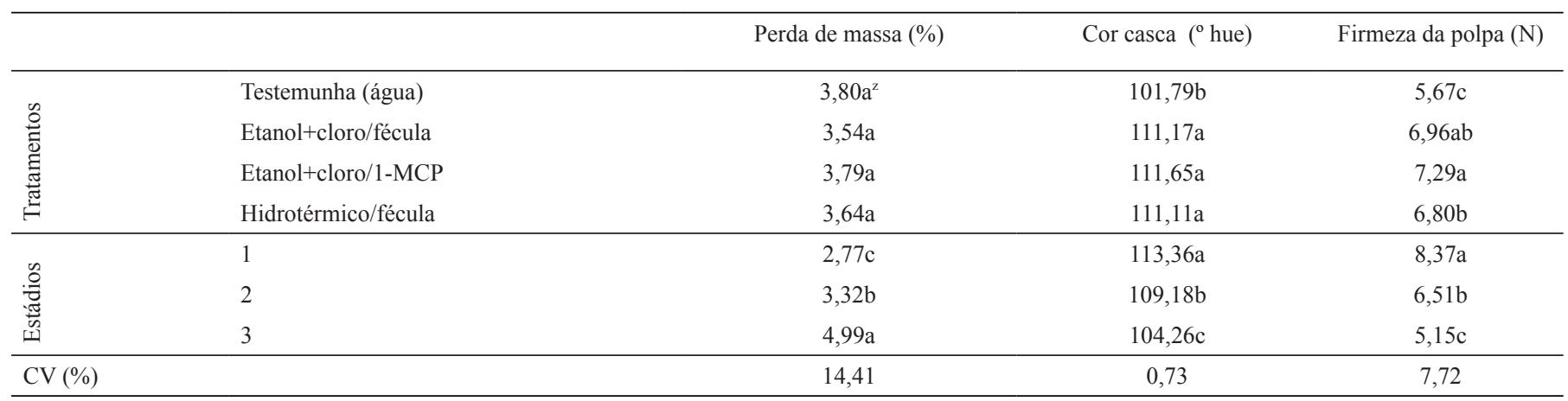

${ }^{\mathrm{y}}$ Média (\%) de três experimentos, com 9 frutos para cada tratamento. ${ }^{2}$ Médias seguidas pela mesma letra na coluna não diferem estatisticamente entre si ao nível de $5 \%$ pelo teste de Tukey.

Tabela 5. Efeito de tratamentos alternativos pós-colheita aplicados em goiabas 'Pedro Sato' com diferentes estádios de maturação nas características químicas, durante oito dias de armazenamento a $22^{\circ} \mathrm{C}$ e $80-85 \%$ de $\mathrm{UR}^{\mathrm{y}}$

\begin{tabular}{|c|c|c|c|c|}
\hline & & Sólidos solúveis $\left({ }^{\circ} \mathrm{Brix}\right)$ & $\begin{array}{l}\text { Acidez tituável } \\
\text { (\% ác. cítrico) }\end{array}$ & $\begin{array}{l}\text { Àcido ascórbico } \\
\quad\left(\mathrm{mg} 100 \mathrm{~g}^{-1}\right)\end{array}$ \\
\hline \multirow{3}{*}{ 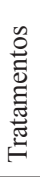 } & Testemunha (água) & $9,56 \mathrm{a}^{\mathrm{z}}$ & $0,57 \mathrm{~b}$ & $60,12 a$ \\
\hline & Etanol+cloro/1-MCP & $9,76 \mathrm{a}$ & $0,62 \mathrm{a}$ & $59,91 \mathrm{a}$ \\
\hline & Hidrotérmico/fécula & $9,67 \mathrm{a}$ & $0,58 \mathrm{~b}$ & $57,68 \mathrm{a}$ \\
\hline 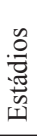 & 3 & $9,55 b$ & $0,51 \mathrm{c}$ & $55,83 \mathrm{~b}$ \\
\hline \multicolumn{2}{|c|}{ CV $(\%)$} & 1,77 & 1,69 & 4,88 \\
\hline
\end{tabular}

${ }^{y}$ Média (\%) de três experimentos, com 9 frutos para cada tratamento. ${ }^{2}$ Médias seguidas pela mesma letranão diferem estatisticamente entre si ao nível de $5 \%$ pelo teste de Tukey.

Tabela 6. Coeficientes de correlação (r) entre a incidência da antracnose e parâmetros físico-químicos em goiabas 'Pedro Sato' amostradas em três estádios de maturação, segundo a cor da casca ( 1 =verde escuro; $2=$ verde claro e $3=$ verde-amarelo) e submetidas a diferentes tratamentos pós-colheita, durante oito dias de armazenamento a $22^{\circ} \mathrm{C}$ e $80-85 \%$ de $\mathrm{UR}^{\mathrm{y}}$

\begin{tabular}{|c|c|c|c|c|c|}
\hline \multirow[t]{2}{*}{ Tratamentos } & \multicolumn{5}{|c|}{ Parâmetros físico-químicos } \\
\hline & Cor da casca & Firmeza da polpa & Sólidos solúveis & Acidez titulável & Ácido ascórbico \\
\hline \multicolumn{6}{|l|}{ Goiabas no estádio 1 de maturação } \\
\hline Etanol+cloro/1-MCP & $-0,83 *$ & $-0,85^{*}$ & 0,30 & $-0,33$ & 0,19 \\
\hline Hidrotérmico/fécula & $-0,74$ & $-0,23$ & $-0,12$ & 0,64 & 0,21 \\
\hline Etanol+cloro/1-MCP & $-0,94 *$ & $-0,92 *$ & 0,03 & 0,03 & 0,51 \\
\hline Hidrotérmico/fécula & $-0,97 *$ & $-0,75$ & $-0,27$ & 0,10 & 0,50 \\
\hline \multicolumn{6}{|l|}{ Goiabas no estádio 3 de maturação } \\
\hline Etanol+cloro/fécula & $-0,73$ & $-0,79$ & $-0,02$ & 0,28 & 0,22 \\
\hline
\end{tabular}

* Significativo a 0,05 .

Sato'. Goiabas tratadas com 1-MCP apresentam um maior período de conservação em função do atraso no amadurecimento (3). O 1-MCP é um composto volátil que tem demonstrado ser um potente inibidor da ação do etileno na célula. Este produto se liga ao sítio de ligação do etileno na célula, inibindo seu estímulo fisiológico sobre o amadurecimento (24). Menor incidência de goiabas com podridões, causadas principalmente por $C$. gloeosporioides, também foi constatada por Bassetto et al. (3) após tratamento com 1-MCP.

Recobrimentos comestíveis podem contribuir para aumentar o período de conservação das goiabas, a exemplo da fécula de mandioca 
que tem sido citada como a matéria-prima mais adequada por formar películas transparentes, eficientes barreiras à perda de água, proporcionando bom aspecto e brilho, tornando frutas e hortaliças comercialmente atrativas. $\mathrm{O}$ biofilme de fécula é facilmente removido com água e apresenta-se como um produto de baixo custo. Resultados satisfatórios na conservação de goiabas 'Kumagai' com fécula de mandioca, através do atraso no amadurecimento e consequentemente no aparecimento de podridões, inclusive com um maior controle da incidência $(77,7 \%)$, foram observados por Cerqueira (7).

$\mathrm{O}$ tratamento hidrotérmico controla as doenças desde que as infecções estejam nas primeiras camadas da epiderme do fruto. Pode atuar também inibindo o amadurecimento, atrasando o colapso e a extinção de compostos antifúngicos pré-formados (17). Segundo Pascholati et al. (19), pode induzir a síntese de compostos antifúngicos, como fitoalexinas ou proteínas relacionadas à patogênese. Atraso no amadurecimento e controle da antracnose, com redução do diâmetro das lesões em goiabas inoculadas e no número de lesões naturais foram constatados por Cruz et al. (11).

Em goiabas 'Kumagai' submetidas à imersão em etanol 50\%, Ponzo (21) observou redução da antracnose em frutos inoculados com C. gloeosporioides, sem alterar os parâmetros físico-químicos dos frutos. O etanol é muito utilizado no processo de desinfestação, ou seja, processo que elimina os micro-organismos, atuando na desnaturação das proteínas e remoção de lipídios da membrana plasmática ou parede celular do microorganismo (10), colaborando também na quebra da tensão superficial do fruto e com isso, possivelmente, favorecendo a atuação do segundo desinfetante, no caso o cloro. Diferentemente do observado no presente trabalho, Cruz et al. (11) constataram controle da antracnose com fosfitos e cloreto de cálcio, através de redução do diâmetro da lesão da antracnose, em frutos inoculados com $C$. gloeosporioides.

A ocorrência da antracnose foi superior na segunda etapa dos experimentos, relacionado possivelmente a elevação em $3^{\circ} \mathrm{C}$ da temperatura de armazenamento dos frutos, de 22 para $25^{\circ} \mathrm{C}$. Em estudo da infecção da antracnose da goiaba, máxima germinação e formação de apressório de C. gloeosporioides foi observada a $25^{\circ} \mathrm{C}$, assim como a infecção de goiabas pelo patógeno foi crescente até $30^{\circ} \mathrm{C}(25)$.

Os tratamentos foram, de maneira geral, mais eficientes em reduzir a incidência de antracnose quando em associação, principalmente etanol+cloro/fécula e hidrotérmico/fécula. Cruz et al. (11) obtiveram maior controle da antracnose quando associou o tratamento hidrotérmico seguido dos tratamentos 1-MCP ou fosfito de potássio.

A incidência de antracnose foi crescente com a maturação das goiabas. Resultados semelhantes foram obtidos por Azzolini et al. (2) em que goiabas no estádio de maturação 1 apresentaram período de comercialização de seis dias a $25^{\circ} \mathrm{C}$, enquanto frutos nos estádios 2 e 3 tiveram este período reduzido para quatro e dois dias, respectivamente, devido, principalmente, à ocorrência de podridões. Considerando que as podridões desqualificam a fruta para comercialização e não devem ultrapassar $20 \%$ durante a vida útil (20), a viabilidade dos frutos no tratamento testemunha ficou entre dois e quatro dias, em função do estádio de maturação. Contudo, com as associações de tratamentos conseguiu-se atrasar em dois ou até quatro dias o aparecimento dos sintomas de antracnose em frutos armazenados a 22 ou $25^{\circ} \mathrm{C}$.

Todos os tratamentos, principalmente o 1-MCP foram eficientes em manter a qualidade físico-química das goiabas, retardando a mudança de coloração da casca e contribuindo para a retenção da firmeza da polpa, e consequentemente, estando diretamente relacionado à inibição do aparecimento dos sintomas da doença.
A perda de massa em frutos é oriunda da respiração e transpiração. A possível redução desta perda por meio da aplicação do 1-MCP está relacionada ao fato do mesmo reduzir a respiração. A respiração reduz a massa do fruto, mas em menor proporção que a transpiração. Isso pode explicar o fato do 1-MCP não ter sido eficaz em retardar a perda de massa. Bassetto et al. (3) também não verificou redução da perda de massa em goiabas tratadas com 1-MCP. Já os recobrimentos a base de polissacarídeos, como é o caso da fécula, possuem uma boa barreira ao $\mathrm{O}_{2}$ e $\mathrm{CO}_{2}$, mas uma fraca barreira ao vapor d'água (13). Isso pode explicar o fato da fécula não ter sido eficaz em retardar a perda de massa. Cerqueira (7) também observou pequena redução da perda de massa em goiabas 'Kumagai' armazenadas a $22^{\circ} \mathrm{C}$ e tratadas com fécula a $2 \%$.

Os principais processos envolvidos na perda da coloração verde dos frutos durante o amadurecimento são a degradação da clorofila e a síntese de caroteno (16). A atividade da clorofilase, assim como de outras enzimas relacionadas ao processo de amadurecimento dos frutos dependem do etileno. Azzolini et al. (2), observaram que a cor da casca apresentou diminuição dos valores de ângulo $\left({ }^{\circ} \mathrm{h}\right)$ em todos os estádios de maturação durante o armazenamento, indicando a mudança de cor verde para amarela.

Blankenship \& Dole (4) relatam que o 1-MCP tem-se mostrado bastante eficiente em reduzir a produção e bloquear a ação do etileno em diversas espécies vegetais. Cerqueira et al. (8) verificaram que quanto maior a concentração de 1-MCP, melhor seu desempenho na retenção da cor verde da casca em goiabas 'Kumagai'. Em relação à firmeza da polpa, Bassetto et al. (3) também verificaram que goiabas tratadas com $900 \mathrm{~nL} \mathrm{~L}^{-1}$ de 1-MCP por três horas, mantiveram a firmeza por oito dias. A eficácia dos tratamentos a base de fécula em atrasar o amadurecimento dos frutos, deve-se à barreira formada pelo biofilme aos gases, prociciando redução da respiração dos frutos (13).

O teor de açúcares aumenta com o amadurecimento das frutas por meio de processos biossintéticos ou pela degradação de polissacarídeos. Esse aumento pode ser devido à conversão de polissacarídeos da parede celular em açúcares solúveis. No entanto, na senescência ocorre redução no teor de açúcar. Jacomino et al. (15) relatam que após a colheita o teor de sólidos solúveis em goiaba parece não sofrer alterações significativas, tal fato pode ser explicado pelo baixo teor de amido em goiabas. Azzolini et al. (2), relataram poucas mudanças no teor de sólidos solúveis em função do estádio de maturação, a exemplo do observado no presente estudo em que o teor de sólidos solúveis dos frutos dos estádios 2 e 3 diferenciaram em menos de $0,3^{\circ}$ Brix do estádio 1.

Os teores de sólidos solúveis dos frutos não foram influenciados pelos tratamentos, divergindo do encontrado por outros autores. Cerqueira et al. (8) observaram menor teor de sólidos solúveis em goiabas tratadas com 1-MCP. Singh \& Pal (23) verificaram que em goiabas 'Safeda' o tratamento com 1-MCP restringiu o aumento de sólidos solúveis para frutos armazenados a $10^{\circ} \mathrm{C}$, mas no armazenamento em temperatura ambiente o teor de sólidos solúveis aumentou.

A maior acidez no tratamento com 1-MCP pode ser explicada pela retenção do amadurecimento. Bassetto et al. (3) relataram maior acidez em goiabas tratadas com 1-MCP e armazenadas em temperatura ambiente. A redução nos teores de acidez titulável com o avanço do estádio de maturação dos frutos é decorrente da metabolização de ácidos voláteis e não voláteis no processo de amadurecimento (9).

Os tratamentos não influenciaram o teor de ácido ascórbico dos frutos. Bassetto et al. (3) também verificaram que as quantidades de ácido ascórbico não foram influenciadas pelo 1-MCP em goiabas 'Pedro Sato'. O estádio de maturação influenciou o teor de ácido 
ascórbico, sendo maiores teores encontrados nos frutos dos estádios 1 e 2. Esses resultados divergem dos encontrados por Azzolini et al (2) os quais verficaram aumento do teor de ácido ascórbico com o avanço da maturação.

Observou-se correlação entre o estádio de maturação das goiabas, expresso pela cor da casca, e a ocorrência de antracnose, fato também constatado por Azzolini et al. (2). Associações entre o aumento das infecções com mudanças em parâmetros físico-químicos foram relatadas em maçã (22). Nos frutos submetidos aos tratamentos, à correlação entre a antracnose e os parâmetros cor da casca e firmeza da polpa, evidencia que a redução da doença nos tratamentos está diretamente relacionada ao atraso da maturação dos frutos. Segundo Cavalini et al. (6), a cor da casca e a firmeza da polpa são os índices de maturação mais adequados para goiaba, permitindo diferenciar os estádios de maturação e apresentam boa correlação entre si.

Em vista da importância da antracnose como doença pós-colheita da goiabeira, preconiza-se que medidas sejam adotadas visando uma maior conservação do fruto, a exemplo das associações de tratamentos que se destacaram no controle da doença, etanol+cloro/1-MCP nos estádios $1 \mathrm{e}$ 2 de maturação do fruto e hidrotérmico/fécula de mandioca no estádio 3 , prolongando a vida útil dos frutos em até quatro dias.

\section{AGRADECIMENTOS}

À FAPESP (Proc. 2012/07207-7) pelo apoio financeiro concedido ao projeto.

\section{REFERÊNCIAS}

1. AgRIANUAL, Anuário da Produção Brasileira. São Paulo: FNP Consultoria e Comércio, 2014. 460p.

2. Azzolini, M.; Jacomino, A.P.; Bron, I.U. Índices para avaliar qualidade pós-colheita de goiabas em diferentes estádios de maturação. Pesquisa Agropecuária Brasileira, Brasília, v.39, n.2, p.139-145, 2004.

3. Bassetto, E.; Jacomino, A.P.; Pinheiro, A.L. Conservation of 'Pedro Sato' guavas under treatment with 1-methylcyclopropene. Pesquisa Agropecuária Brasileira, Brasília, v.40, p.433-440, 2005.

4. Blankenship, S.M.; Dole, J.M. 1-Methylcyclopropene: a review. Postharvest Biology and Technology, Amsterdam, v.28, p.1-25, 2003.

5. Carvalho, C.R.L.; Mantovani, D.M.B.; Carvalho, P.R.N. Análises químicas de alimentos: manual técnico. Campinas: Instituto de Tecnologia de Alimentos, 1990. 121p.

6. Cavalini, F.C.; Jacomino, A.P.; Lochoski, M.A.; Kluge, R.A.; Ortega, E.M.M. Maturity indexes for Kumagai and Paluma guavas. Revista Brasileira de Fruticultura, Jaboticabal, v.28, p.176-179, 2006.

7. Cerqueira, T.S. Recobrimentos comestíveis em goiabas cv. Kumagai. 2007. 69f. Dissertação (Mestrado em Fisiologia e Bioquímica de Plantas) - Escola Superior de Agricultura "Luiz de Queiroz", Universidade de São Paulo, Piracicaba

8. Cerqueira, T.S.; Jacomino, A.P.; Sasaki, F.F.; Amorim, L. Controle do amadurecimento de goiabas 'Kumagai' tratados com 1-Metilciclopropeno. Revista Brasileira de Fruticultura, Jaboticabal, v.31, p.687-692, 2009.
9. Chitarra, M.I.F.; Chitarra, A.B. Pós-colheita de frutas e hortaliças - fisiologia e manuseio. $2^{\mathrm{a}}$ ed. Lavras: EDUFLA, 2005. 875p.

10. Costa, A.J.F.; Kalil, E.M. Desinfecção e esterilização Acta Ortopédica Brasileira, São Paulo, v.2, p.1-4, 1994.

11. Cruz, A.F.; Medeiros, N.L.; Benedet, G.L.; Araujo, M.B.; Uesugi, C.H.; Ferreira, M.A.S.V.; Peixoto, J.R.; Blum, L.E.B. Control of post-harvest anthracnose infection in guava (Psidium guajava) fruits with phosphites, calcium chloride, acetyl salicylic acid, hot water, and 1-MCP. Horticulture Environment and Biotechnology, New York, v.56, p.330-340, 2015.

12. Fischer, I.H.; Almeida, A.M.; Arruda, M.C.; Bertani, M.A.R.; Garcia, M.J.M.; Amorim, L. Danos em pós-colheita de goiabas na Região do Centro-Oeste Paulista. Bragantia, Campinas, v.70, p.570-576, 2011.

13. Garcia, M.A.; Martino, M.N.; Zaritzky, N.E. Plasticized starch-based coatings to improve strawberry (Fragaria $\mathrm{x}$ Ananassa) quality and stability. Journal of Agricultural and Food Chemistry, Washington, v.46, p.3578-3767, 1998.

14. Hojo, R.H., Chalfun, N.N.J., Hojo, E.T.D.; Veiga, R.D., Paglis, C.M., Lima, L.C.O. Produção e qualidade dos frutos da goiabeira 'Pedro Sato' submetida a diferentes épocas de poda. Pesquisa Agropecuária Brasileira, Brasília, v.42, p.357-362, 2007.

15. Jacomino, A.P.; Sigrist, J.M.M.; Sarantópoulos, C.I.G.L.; Minami, K.; Kluge, R.A. Embalagens para conservação refrigerada de goiabas. Revista Brasileira de Fruticultura, Jaboticabal, v.23, n.1, p.50-54, 2001.

16. Khandaker, M.M., Boyce, A.N., Osman, N., Golam, F., Rahman, M.M., Sofian-Azirun, M. Fruit development, pigmentation and biochemical properties of wax apple as affected by localized application of $\mathrm{GA}_{3}$ under field conditions. Brazilian Archives of Biology and Technology, Curitiba, v.56, p11-20, 2013.

17. Lurie, S. Postharverst heat treatment of horticultural crops. Horticultural Reviews, New York, v.22, p.91-118, 1998.

18. Ojeda, M.R. Utilização de ceras, fungicidas e sanitizantes na conservação de goiabas 'Pedro Sato' sob condição ambiente. 2001. 57f. Dissertação (Mestrado em Fitotecnia) - Escola Superior de Agricultura "Luiz de Queiroz", Universidade de São Paulo, Piracicaba.

19. Pascholati, S.F.; Lia, P.; Benato, E.A.; Camili, E.C. O fenômeno da indução de resistência e o controle das doenças de pós-colheita. In: Reunião Brasileira sobre indução de resistência em plantas. Lavras: UFLA, 2004. p.3-7.

20. Paull, R.E. Effects of temperature and relative humidity on fresh commodity quality. Postharvest Biology \& Technology, Amsterdam, v.15, p.263-277, 1999.

21. Ponzo, F.S. Agentes alternativos no controle pós-colheita da antracnose em goiabas 'Kumagai'. 2009. 77f. Dissertação (Mestrado em Tecnologia da Produção Agrícola) - Instituto Agronômico, Campinas.

22. Sharma, R.L.; Kaul, J.L. Susceptibility of apples to brown rot in relation to quantitative characters. Indian Phytopathology, Nova Delhi, v.43, n.1, p.113-115, 1988

23. Singh, S.P.; Pal, R.R. Response of climacteric-type guava (Psidium guajava L.) to postharvest treatment with 1-MCP. Postharvest Biology and Technology, Amsterdam, v.47, n.3, p.307-314, 2008.

24. Sisler, E.C.; Serek, M. Inhibitors of ethylene responses in plants at the receptor level: recent developments. Plant Physiology, Rockville, v.100, p.577-582, 1997.

25. Soares, A.R.; Lourenço, S.A.; Amorim, L. Infecção de goiabas por Colletotrichum gloeosporioides e Colletotrichum acutatum sob diferentes temperaturas e molhamentos. Tropical Plant Pathology, Brasília, v.33, n.4, p.265-272, 2008.

26. Zar, J.H. Biostatistical analyis. New Jersey: Prentice-Hall, 1999. 663 p. 